\title{
Kidney damage in hypertensive adults in primary
}

\section{care}

\begin{abstract}
Summary
Chronic kidney disease (CKD) is a public health problem that causes morbidity and mortality and high costs, with a very variable incidence and prevalence among countries, with scarce information in stages prior to dialysis, remaining as an underdiagnosed and late reference disease.
\end{abstract}

Objectives: To estimate the frequency of kidney damage in adults with hypertension in the Family Medicine Unit (UMF) Number 28 of the Instituto Mexicano del Seguro Social (IMSS).

Methods: A descriptive, observational, cross-sectional and prospective study was carried out, including 164 randomly selected individuals with hypertension, who were evaluated for renal function with the estimation of Glomerular Filtration Rate with the Chronic Kidney Disease-Epidemiology Collaboration formula (CKD-EPI), and the Albuminuria/Creatinuria Ratio (ACR), stratifying kidney disease according to the recommendations of the Kidney Disease Improving Global Outcomes foundation. Descriptive statistics were used with the statistical program SPSS v21.

Results: The frequency of CKD was $6.70 \%$, lower than that reported in other investigations.

Conclusion: This research reports the lowest frequency in the literature, with the use of two detection methods that help reduce the under-diagnosis of kidney disease, since in routine clinical practice only Glomerular Filtration Rate in the assessment of renal function is estimated, highlighting the importance of an internationally standardized assessment.

Keywords: kidney diseases, hypertension, albuminuria, descriptive statistics, chronic kidney disease, creatinuria ratio, routine clinical practice, glomerular filtration rate, collaboration formula
Volume 2 Issue 6 - 2018

\author{
Fernando Rodríguez Rojas,' María Elena \\ Haro Acosta, ${ }^{2}$ Alberta Silvia Laborde López, ${ }^{3}$ \\ Guadalupe Ortega Vélez, ${ }^{4}$ Alberto Barreras \\ Serrano, ${ }^{5}$ Vanessa Johanna Caro ${ }^{6}$ \\ 'Resident of Family Medicine, Family Medicine Unit No \\ 28 of Mexican Institute of Social Security (IMSS), Calzada \\ Independencia, México \\ 2D.C. and Pediatrician, Coordinator in Health Research, \\ Delegación Baja California of IMSS, México \\ ${ }^{3}$ Nephrologist, General Hospital No. 30 of IMSS, México \\ ${ }^{4}$ Family doctor, Family Medicine Unit No 28 of Mexican Institute \\ of Social Security (IMSS), México \\ ${ }^{5}$ Researcher in the Veterinary Faculty of UABC, Km. 3.5, \\ Carretera San Felipe, México \\ ${ }^{6}$ Family doctor, Family Medicine Unit No 28 of Mexican Institute \\ of Social Security (IMSS), México
}

\author{
Correspondence: María Elena Haro Acosta, D.C. and \\ Pediatrician. Coordinator in Health Research, Delegación Baja \\ California of IMSS, Calzada Cuauhtémoc No.300, Colonia \\ Aviación, C.P. 21230 , Mexicali, B.C. México, \\ Email maria.haroa@imss.gob.mx, lenaharo@live.com.mx
}

Received: October II, 2018 | Published: December 10, 2018

\section{Introduction}

Chronic Kidney Disease (CKD) is defined as the presence of alterations in renal structure or function for more than three months and with implications for health, ${ }^{1}$ it is considered a public health problem that causes morbidity and mortality and high costs, ${ }^{2,3}$ and it occupies the 27 th place in the list of causes of mortality worldwide, with an incidence and prevalence of end-stage renal disease that differs substantially between countries and regions, ${ }^{4,5}$ the available information on CKD in stages prior to dialysis is scarce, remaining a disease underdiagnosed and with late referral. ${ }^{2-6}$ The risk of developing CKD is increased in some people in whom a greater effort should be made in the early detection of this condition, especially in those with Diabetes Mellitus (DM), Systemic Arterial Hypertension (SAH), over 60 years of age, and with a family history of CKD. With regard to SAH defined as: a sustained increase in blood pressure with figures $\geq 140 / 90 \mathrm{mmHg}$ with adequate measurement techniques, or greater than or equal to $130 / 80 \mathrm{mmHg}$ according to the literature reviewed. ${ }^{7-10}$ According to the National Survey of Health (ENSANUT) 2012 a prevalence of hypertension in Mexico of $31.5 \%$ in the general population was reported, rising in adults with obesity to $45.3 \%$ and higher in adults with diabetes up to $70.7 \%$, observing hypertensive adults $47.3 \%$ did not know that they suffered from hypertension. ${ }^{11}$ The evaluation of renal function is carried out by means of the estimation of Glomerular Filtration Rate (GFR), currently the method of estimation of the GFR is recommended with the CDK-EPI, ${ }^{1-12}$ and by means of the determination of the ACR (Albuminuria/Creatinine Ratio), considering that the proteinuria is a marker of established renal damage and plays a direct pathogenic role in renal and cardiovascular progression, ${ }^{1-6}$ the standard measurement has usually been the quantification of urine collected during 24 hours, to avoid errors in the collection, the determination of the ACR is recommended, which currently allows us to integrate the classification of the CKD together with the estimation of the GFR. ${ }^{1-6}$ Salvador et al., ${ }^{13}$ in Catalonia report a frequency of CKD of $18.8 \%$ in patients with SAH over 60 years of age, ${ }^{13}$ Da Silva et al., ${ }^{14}$ in Brazil, found a prevalence of CKD of $38.6 \%$ in patients with $\mathrm{SAH},{ }^{14}$ Sánchez et al. ${ }^{15}$ in Mexico, found a $6 \%$ frequency of $\mathrm{CKD}$ in patients with $\mathrm{SAH} .{ }^{15}$ Considering the wide variability in the frequency results of $\mathrm{CKD}$, and the importance of early intervention in early and timely diagnosis, to reduce the progression of kidney disease, improve survival and quality of life, as well as decrease in costs of the treatment, the objective of this study was to estimate the frequency of kidney damage in adults with SAH in UMF 28 of IMSS in 2017.

\section{Material and methods}

The nature of the study is observational, descriptive, crosssectional and prospective. Data was obtained from records of adult patients between 18 and 80 years of age, with a diagnosis of arterial hypertension who attended consultations at the UMF Number 28 of IMSS in Mexicali Baja California, from August 2017 to January 2018.

\section{Sample size}

The sample size was calculated for a simple random sampling by attributes, considering that in our medical care unit there is a 
population of 167,552 individuals. The sampling frame consisted of all patients diagnosed with SAH without other comorbidities in the UMF 28, with a total of 11,040 patients. The formula for estimating a proportion in a finite population, a confidence interval of $95 \%$ was considered, accuracy in the estimation of $5 \%$, and a prevalence value in the literature of $12 \%^{16-18}$ for CKD in patients with $\mathrm{SAH}$.

$$
n=\frac{N Z_{\alpha}^{2} p(1-p)}{d^{2}(N-1)+Z_{\alpha}^{2} p(1-p)}=160 \text { patients }
$$

The inclusion criteria were adults older than 18 and younger than 80 , and those without comorbidities that could reflect a rise in proteinuria (heart failure, collagen disease, DM). Patients with incomplete laboratory analysis results were excluded.

\section{Obtaining information}

Primary care clinics records of patients with SAH without other comorbidities who attended the consultation during the study period were randomly selected; 4 patients per clinic of the 44 existing clinics in the FMU number 28 were randomly included, with a total of 174 of which 12 patients were excluded due to insufficient information, with a final sample of 164. Each patient was informed by their doctor about the need to perform laboratory tests to evaluate kidney function. As a first step, in the unit's laboratory, serum creatinine was determined using a standardized modified Jaffé method, ${ }^{19}$ as well as the determination of albuminuria and creatinuria with the turbidimetric method of immunoinhibition. ${ }^{19,20}$ In a second stage, three months later, the determinations were repeated in those patients in whom biochemical alterations were found. Evaluation of renal function was performed with the estimation of the GFR with the formula CKD-EPI, ${ }^{12}$ and the ACR, stratifying the kidney disease according to the recommendations of the KDIGO. ${ }^{1}$ The study variables were: estimated GFR, the ACC, age, gender, body mass index, and the years since the diagnosis of SAH.

\section{Statistic analysis}

For the information analysis, descriptive statistics were used: measures of central tendency and dispersion for quantitative variables and percentages for qualitative variables. The software used was SPSS version 21. This study does not contradict the guidelines of the Ley General de Salud en Materia de Investigación para la Salud (General Law of Health in the Matter of Research for Health) and with local norms and manuals.

\section{Results}

Table 1 presents the general characteristics of patients with SAH in the sample. For the total number of patients included, the average age was $58.51 \pm 12.7$ years, with an average disease time of $8.99 \pm 9.5$ years, and an average BMI of $31.5 \pm 5.5 \mathrm{~kg} / \mathrm{m} 2$. By gender, $62 \%$ were women and $38 \%$ men. Of the patients studied, a CKD frequency of $6.70 \%$ (11 patients) was found whose general characteristics are presented in Table 2, classified by gender. Regarding GFR, an increased frequency was observed in the G3a category, and in the category of persistent albuminuria $\mathrm{A} 2$ was more frequent. The age with the greatest presence of CKD was in those older than 50(10/11). Of the total number of patients diagnosed with CKD, 7/11 resulted with abnormal GFR. However, when the ACR was included as a diagnostic complement, of the 7 patients with abnormal GFR, 2 showed altered ACR values. But 4 patients resulted with altered ACR (4/11) and normal GFR, which routinely leaves $36 \%$ of patients with under diagnosis of CKD.
Table I General characteristics of patients with $\mathrm{SAH}$

\begin{tabular}{|c|c|c|c|}
\hline & Men & Women & Total \\
\hline No. of patients ${ }^{a}$ & $62(37.8)$ & 102 (62.2) & 164 \\
\hline Age b (years) & 59.91 (14.28) & $57.65(11.74)$ & $58.5 \mathrm{I}(12.76)$ \\
\hline \multicolumn{4}{|l|}{ Age group ${ }^{a}$} \\
\hline $18-29$ years & $3(1.82)$ & ND & $3(1.82)$ \\
\hline $30-39$ years & $3(1.82)$ & $7(4.26)$ & $10(6.09)$ \\
\hline $40-49$ years & $6(3.65)$ & $16(9.75)$ & $22(13.42)$ \\
\hline $50-59$ years & $15(9.14)$ & $37(22.56)$ & $52(31.70)$ \\
\hline $60-69$ years & $16(9.75)$ & $22(13.4 I)$ & $38(23.17)$ \\
\hline $70-79$ years & $19(11.58)$ & $20(12.19)$ & $39(23.78)$ \\
\hline \multicolumn{4}{|l|}{ BMI a } \\
\hline Underweight $(<18.5)$ & ND & ND & ND \\
\hline Normal (I8.5-24.9) & $7(4.26)$ & $13(7.92)$ & $20(12.19)$ \\
\hline Overweight (25-25.9) & $20(12.19)$ & $23(14.02)$ & $43(26.21)$ \\
\hline GI Obesity (30-34.9) & $27(16.46)$ & $35(21.34)$ & $62(37.80)$ \\
\hline GIl Obesity (35-39.9) & $7(4.26)$ & $22(|3.4|)$ & $29(17.68)$ \\
\hline GIII Obesity (>40) & I $(0.60)$ & $9(5.48)$ & $10(6.09)$ \\
\hline \multicolumn{4}{|l|}{ Laboratory Analysis } \\
\hline GFRe (CKD-EPI) ${ }^{b, c}$ & 89.18 (18.73) & $93.87(19.64)$ & $92.67(18.76)$ \\
\hline ACR $(m g / g)^{b, d}$ & 8.75 (18.69) & $14.19(38.51)$ & I I.72 (32.49) \\
\hline
\end{tabular}

${ }^{a}$ Values expressed as the total number of cases and percentage in parentheses. bValues expressed as mean and standard deviation in parentheses. 'GFRe (CKD-EPI): Estimated glomerular filtration expressed in $\mathrm{ml} / \mathrm{min} / \mathrm{I} .73 .{ }^{\mathrm{d}} \mathrm{ACR}$ : Albumin/creatinine ratio in an isolated sample of urine expressed in $\mathrm{mg} / \mathrm{g}$, ND: Not Determined.

Table 2 General characteristics of patients with CKD

\begin{tabular}{|c|c|c|c|}
\hline & Hombres & Mujeres & Total \\
\hline No. of patients ${ }^{a}$ & $4(36.37)$ & 7 (63.63) & II (100) \\
\hline Age b (years) & $69.25(12.55)$ & $61(10.72)$ & $64(11.55)$ \\
\hline \multicolumn{4}{|l|}{ Age group ${ }^{a}$} \\
\hline $40-49$ años & ND & I (9.09) & I (9.09) \\
\hline $50-59$ años & I (9.09) & $2(18.18)$ & $3(27.27)$ \\
\hline $60-69$ años & ND & $3(27.27)$ & $3(27.27)$ \\
\hline $70-79$ años & $3(27.27)$ & I (9.09) & $4(36.36)$ \\
\hline \multicolumn{4}{|l|}{ BMI a } \\
\hline Normal (I8.5-24.9) & ND & $I(9.09)$ & I (9.09) \\
\hline Overweight (25-25.9) & I (9.09) & I (9.09) & $2(18.18)$ \\
\hline GI Obesity (30-34.9) & $3(27.27)$ & $2(18.18)$ & $5(45.45)$ \\
\hline GIl Obesity (35-39.9) & ND & $2(18.18)$ & $2(18.18)$ \\
\hline GIII Obesity (>40) & ND & I (9.09) & I (9.09) \\
\hline \multicolumn{4}{|l|}{ Laboratory Analysis } \\
\hline GFRe (CKD-EPI) b,c & $55.22(21.68)$ & $68.28(32.58)$ & $64.63(27.55)$ \\
\hline ACR $(m g / g)^{b, d}$ & $42.28(74.92)$ & $111.69(104.11)$ & $75.78(107.12)$ \\
\hline
\end{tabular}

aValues expressed as the total number of cases and percentage in parentheses. bValues expressed as mean and standard deviation in parentheses.

'GFRe (CKD-EPI): Estimated glomerular filtration expressed in $\mathrm{ml} / \mathrm{min} / \mathrm{I} .73$. ${ }^{d} A C R:$ Albumin/creatinine ratio in an isolated sample of urine expressed in $\mathrm{mg} / \mathrm{g}$.

ND Not Determined 


\section{Discussion}

The frequency of CKD in patients with SAH when including VGF estimated by CKD-EPI and ACR was 6.70\% (11/164); less than the report generated in Brazil with 38.6\% (113/293). ${ }^{14}$ The high value in the Brazilian report is due to differences and biases in the procedures used. In this study, the frequency of persistent albuminuria in hypertensive patients was $3.65 \%$, lower than that reported by Robles et al., ${ }^{12}$ in Badajoz, Spain where it was $12.4 \%$, this difference is explained by differences in the techniques and procedures used, for example, the determination of proteinuria in a semiquantitative manner. The frequency of CKD-EPI ERC by Glomerular Filtration found in this investigation was $4.2 \%$, lower than that reported by Zúñiga et al. ${ }^{17}$ in Concepción, Chile where they found a prevalence of $12.1 \%$ estimating the GFR with the formula MDRD-4; this is due to the different formula used to estimate GFR, since MDRD-4 overestimates kidney disease in stages prior to dialysis, however, currently the recommendation by KDIGO is the use of the CKDEPI formula, as in present study. ${ }^{1-11}$ Sánchez et al. ${ }^{15}$ in Guanajuato, Mexico conducted an investigation to know the prevalence of CKD in 208 patients with SAH, its result was a frequency of $6.0 \%$, higher than that found in this study of $3.65 \%$ of persistent albuminuria, due to the lack of confirmation at three months of ACR. Salvador et al., ${ }^{13}$ in Catalonia, Spain, report an ERC frequency of $18.8 \%$, using the GFR estimate for the CKD-EPI formula. This higher value than in this study is explained by the lack of confirmation three months after the first determination and the use of patients over 60 years of age. It is important to perform the application of both procedures for the evaluation of renal function in patients with SAH and not limit the use of the estimation of VGF as a diagnosis of CKD, as is routinely done in clinical practice, since more than a third of patients with CKD would be under-diagnosed, therefore subtracting the opportunity for early attention of kidney disease in this group of patients. Early diagnosis of CKD delays the need for renal replacement therapy by improving the patient's quality of life.

\section{Conclusion}

In this study, the frequency of CKD is lower than in the national and international literature, with the use of two detection methods it is favored to reduce the sub-diagnosis, which in clinical practice only estimates the VGF in the evaluation of the function renal even though the international recommendation is to carry out both diagnostic methods (ACR and GFR). Adding the ACR to the estimation of GFR by CKD-EPI in the population with SAH allows the inclusion of patients with under-diagnosis of CKD achieving an early approach to kidney disease and with it a delay in the use of renal replacement therapy. The combined use of estimated GFR and ACR in the first level of care for diagnosis of CKD allows us to fully evaluate this pathology even if we have limited resources allowing timely access to health services for the early approach of kidney disease with a direct benefit to the optimization of resources aimed at improving the health of this population.

\section{Acknowledgments}

None.

\section{Conflicts of interest}

The auhtor declares there is no conflicts of interest.

\section{References}

1. Chronic kidney disease: New KDIGO CKD Clinical Practice Guideline published. Nat Rev Nephrol. 2013;9(3):126.
2. Flores JC, Alvo M, Borja $\mathrm{H}$, et al. Enfermedad Renal Crónica: Clasificación, identificación, manejo y complicaciones. Rev Med Chile. 2009;137:137-177.

3. Rodríguez JM, González R, Albavera C. Comportamiento de la mortalidad por enfermedad renal crónica hipertensiva en la República Mexicana entre 1998-2009. Gac Med Mex. 2013;149(2):152-160.

4. Guía de Práctica Clínica. Prevención, Diagnóstico y Tratamiento de la Enfermedad Renal Crónica Temprana d Renal Crónica Temprana. México; Instituto Mexicano del Seguro Social, 2010. p. 1-95.

5. Jha V, García-García G, Iseki K, et al. Chronic kidney disease: global dimension and perspectives. Lancet. 2013;382(9888):260-272.

6. Gorostidi M, Santamaría R, Alcázar R, et al. Documento de la Sociedad Española de Nefrología sobre las guías KDIGO para evaluación y el tratamiento de la enfermedad renal crónica. Nefrología. 2014;34(3):302316.

7. Brown M. The Seventh Report of the Joint National Committee on Prevention, Detection, Evaluation, and Treatment of High Blood Pressure. JNC 7 Report. Evidence-Based Eye Care. 2003;4(3):179-181.

8. Norma Oficial Mexicana NOM-030-SSA2-2009. Para la prevención, detección, diagnóstico, tratamiento y control de la hipertensión arterial sistémica. Rev Mex Cardiol. 2012;23:4-38.

9. Diagnóstico y Tratamiento de la Hipertensión Arterial en el Primer Nivel de Atención México: Instituto Mexicano del Seguro Social; 08/07/2014 Actualización total. 2012. p. 1-76.

10. Whelton PK, Carey RM, Aronow WS, et al. 2017 ACC/AHA/AAPA/ ABC/ACPM/AGS/APhA/ASH/ASPC/ NMA/PCNA guideline for the prevention, detection, evaluation, and management of high blood pressure in adults: executive summary: a report of the American College of Cardiology/American Heart Association Task Force on Clinical Practice Guidelines. Hypertension. 2018;71:1269-1324.

11. Secretaria de Salud, Encuesta Nacional de Salud y Nutrición. Evidencia para la política pública en salud, hipertensión arterial en adultos mexicanos: importancia de mejorar el diagnóstico oportuno y el control. 2012. p. 1-4.

12. Robles N, Velasco J, Mena C, et al. Microalbuminuria en pacientes diabéticos y en pacientes con hipertensión arterial: estudio de una cohorte de 979 pacientes. Med Clín. 2006;127(20):761-764.

13. Salvador B, Mestre J, Soler M, et al. Enfermedad renal crónica en individuos hipertensos $\geq 60$ años atendidos en Atencion Primaria. NEFROLOGIA. 2017;37(4): 406-414.

14. Da Silva L, Cotta R, Moreira T, et al. Hidden prevalence of chronic kidney disease in hypertensive patients: the strategic role of primary health care. Public Health. 2016;140:250-257.

15. Sánchez D, Cuellar P, Delgadillo MA, et al. Prevalencia de daño renal en pacientes diabéticos y/o hipertensos mediante prueba tamiz (RAC) en una clínica de Guanajuato. Rev Latin Patol Clin. 2012;59(1):28-34.

16. García JA, Rending A, López J. Calculo del tamaño de la muestra en investigación en educación médica. Inv Ed Med. 2013;2(8):217-224.

17. Robles N, Velasco J, Mena C, et al. Microalbuminuria en pacientes diabéticos y en pacientes con hipertensión arterial: estudio de una cohorte de 979 pacientes. Med Clín. 2006;127(20):761-764.

18. Zúñiga C, Müller H, Flores M. Prevalencia de enfermedad renal crónica en centros urbanos de atención primaria. Rev Med Chil. 2011;139:11761184.

19. Chemistry Information Sheet A69463 AJ. CR-E Creatinine. Beckman Coulter Synchron System(s).

20. Chemistry Information Sheet A18520 AL. MA Microalbumin. Beckman Coulter Synchron System(s). 